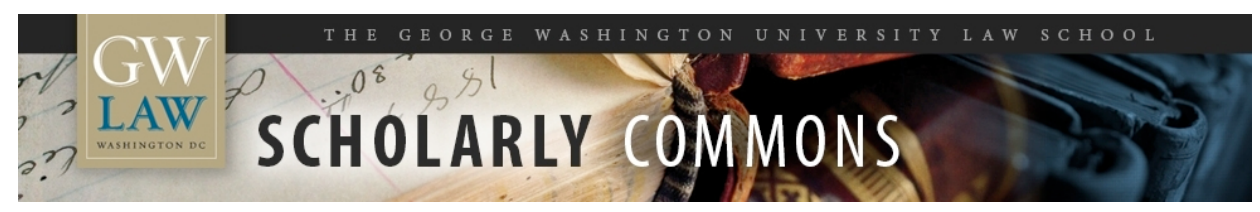

GW Law Faculty Publications \& Other Works

Faculty Scholarship

2019

\title{
Blockchain-Based Insurance
}

Michael B. Abramowicz

George Washington University Law School, abramowicz@law.gwu.edu

Follow this and additional works at: https://scholarship.law.gwu.edu/faculty_publications

Part of the Law Commons

\section{Recommended Citation}

Abramowicz, Michael B., Blockchain-Based Insurance (2019). Blockchain-Based Insurance, in Blockchain and the Constitution of a New Financial Order: Legal and Political Challenges (Ioannis Lianos et al. eds., forthcoming 2019). ; GWU Law School Public Law Research Paper No. 2019-12; GWU Legal Studies Research Paper No. 2019-12. Available at SSRN: https://ssrn.com/abstract=3366603

This Chapter is brought to you for free and open access by the Faculty Scholarship at Scholarly Commons. It has been accepted for inclusion in GW Law Faculty Publications \& Other Works by an authorized administrator of Scholarly Commons. For more information, please contact spagel@law.gwu.edu. 


\title{
Blockchain-Based Insurance
}

\author{
Michael Abramowicz*
}

To date, the insurance industry's interest in the blockchain has focused largely on the possibility of recording insurance entitlements in a transparent way. While the blockchain may produce significant efficiencies of this sort, it has considerably greater transformative potential. Smart contracts could serve as a substitute for insurance companies, conventionally conceived. Such contracts could perform the function of deciding whether claims should paid, without the need for or possibility of judicial intervention. The blockchain and smart contracts are difficult to regulate, because ownership and decisionmaking can be decentralized. Blockchain-based insurance may successfully provide a means of avoiding expensive regulation and could have a competitive advantage over regulated insurance. This article will discuss how blockchain-based insurance might work and will identify some technical challenges and other obstacles that it may face.

\section{Contents}

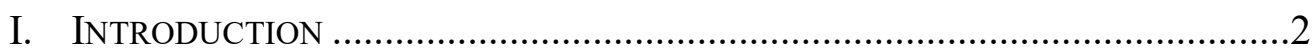

II. How BlockChaIn-BASEd InSURANCE WORKS .....................................

A. With Traditional Insurers ..........................................................8

B. Without Traditional Insurers ..................................................9

1. Pooling Through Smart Contracts .................................................10

2. Underwriting, Investment, and Reinsurance.............................14

\footnotetext{
* Professor of Law, George Washington University. I am grateful to David Abrams and Omri Marian for helpful comments and to participants in workshops at Boston College and George Washington University. All errors are my own.
} 


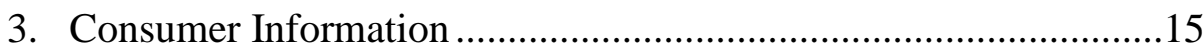

III. THE LAW'S ROLE IN BLOCKCHAIN-BASED INSURANCE ..............................16

A. The Expense of Law ..................................................................17

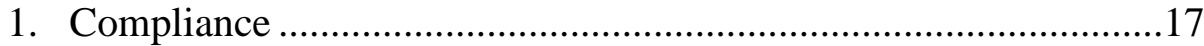

2. Adjudication....................................................................... 17

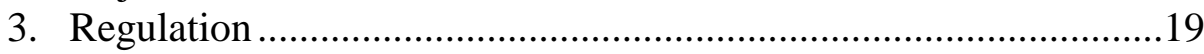

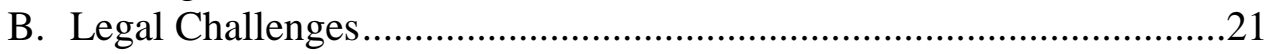

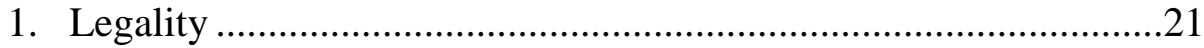

2. Legal Requirements ...........................................................22

3. Legal Support for Blockchain-Based Insurance ..........................22

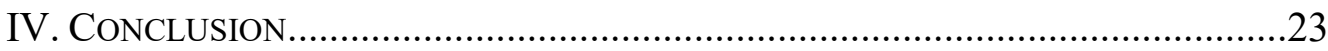

\section{INTRODUCTION}

Insurance is a mechanism for pooling risk. Today, insurance companies are integral to various aspects of risk pooling: They draft, price, and sell policies, and they handle claims. But are insurance companies necessary to the insurance function? This chapter will argue that they are not, and moreover that the blockchain could enable a disruption of the insurance industry. ${ }^{1}$ With a cryptocurrency supporting smart contracts, insureds could pool their resources by digitally agreeing that their cryptocurrency funds will be governed by a protocol. The smart contract would specify the insurable interest - perhaps a particular piece of property or a life - as well as the insurance term, providing a link to documents providing more information. If an insured later claimed a loss, the insurance claim would be resolved pursuant to protocols specified in the smart contract. These protocols ultimately would determine how all the pooled resources would be allocated among the various contributors to the pool (or their beneficiaries) and investors.

The obstacles to blockchain-based insurance are many, but the objections may be grouped crudely in two: first, that insurance companies perform many functions beyond risk pooling and claim resolution; and second, that a blockchain with smart contracts would not be able to perform even these functions effectively. Insurance companies are indeed complex entities. Much of the complexity, however, results from the need to function in a complex legal environment. Insurance companies must comply with detailed legal regimes governing

\footnotetext{
${ }^{1}$ This Article builds on a prior work exploring the possibility of cryptocurrency-based insurance. See Michael Abramowicz, Cryptoinsurance, 50 WAKE FOREST L. REV. 671 (2015).
} 
insurance - not to mention other areas of law, such as antitrust and employment. An insurance company must be prepared to defend denials of claims in court, and litigation is expensive. Moreover, an insurer must draft contracts with due attention to the possibility of eventual adjudication, recognizing the legal principle that ambiguities in insurance policies will be resolved against the insurer, ${ }^{2}$ as well as the practical reality that juries do not much like insurance companies. ${ }^{3}$

It is precisely the cost of this legal complexity that creates the possibility for industry disruption. It would not be easy for the government to regulate insurance purchased via a smart contract. The fundamental problem is that if there is no insurer, the traditional target of regulation is missing. Thus, a government intent on preserving traditional forms of regulation of insurance, including the adjudicative process, would need to target individuals or businesses purchasing insurance on the blockchain, rather than insurers. If the government is not willing to do so, blockchain-based insurance will have a competitive advantage over traditionally provided insurance, namely that it does not need to follow the law. This advantage may exist where regulation prevents insurance from being priced at an actuarially fair rate, for example because of cross-subsidies or because the law requires certain types of coverage that insureds might otherwise prefer not to purchase. ${ }^{4}$ More subtly, blockchain-based insurance may avoid the necessity and thus the expense of traditional adjudication or arbitration.

This observation leads naturally to the second objection, that the blockchain is incapable of substituting for the functions that insurance companies perform. Indeed, it strengthens that objection, because for blockchain-based insurance to be successful, the blockchain will need to substitute not only for insurance companies, but also for the legal system that gives policyholders the confidence that their claims will be paid. Indeed, blockchain-based insurance does not seem possible today. Smart contracts themselves are in their infancy, and existing experiments have shown susceptibility to hacking. ${ }^{5}$ Moreover, cryptocurrencies themselves are highly speculative, ${ }^{6}$ and the last thing that one looking to limit risk would want is

\footnotetext{
${ }^{2}$ See infra note 36 and accompanying text.

${ }^{3}$ For convincing empirical evidence that juries are more likely to find liability when defendants are insured, see Alan Calnan, The Insurance Exclusionary Rule Revisited: Are Reports of Its Demise Exaggerated?, 52 OHIO ST. L.J. 1177, 1203-04 (1991). See also Valuerie P. Hans, The Illusions and Realities of Jurors' Treatment of Corporate Defendants, 48 DEPAUL L. REV. 327 (1998).

${ }^{4}$ See infra Part III.A.3.

5 See, e.g., Stan Schroeder, Not Again: Hackers Steal \$32 Million Worth of Ethereum, MASHABLE, July 20, 2017, 2017 WLNR 22084860.

${ }^{6}$ There is considerable recent debate about whether Bitcoin is overvalued. See Tyler Cowen, Is Bitcoin Just a Bubble?, MARGINAL REVOLUTION (blog), Nov. 30, 2017, http://marginalrevolution.com/marginalrevolution/2017/11/bitcoin-just-bubble.html.
} 
to have one's risk cushion invested in a volatile asset. These problems might, however, be overcome with time. Smart contracts will improve with technological development and formal proofs verifying their properties. $^{7}$ Nascent cryptocurrencies include mechanisms making it possible to hold assets denominated in dollars or other traditional currencies. ${ }^{8}$ Even if such stability is impossible in a traditional cryptocurrency, if a single country were to adopt a cryptocurrency as its national currency, that currency's status as fiat could establish sufficient stability for smart contracts.

Even with a hypothetically functioning and stable cryptocurrency with smart contract capabilities, mimicking the functions of insurance companies and the legal system will not be straightforward. Perhaps the simplest design would be to create a pure fund, where all pooled resources will be returned to insureds in proportion to their realized losses. But even this approach requires a mechanism to measure those losses and to do so without courts. A pool of contracts could specify an arbitrator with the power to determine losses. ${ }^{9}$ The arbitrator might be paid by a party filing a claim, with the payment proportional to the claim made. If there is concern that an arbitrator might have a conflict of interest (perhaps the arbitrator has surreptitiously contributed to the pool), a variety of mechanisms can be used to limit the power of any one cryptocurrency owner. For example, an appellate system could be based on relatively simple voting rules, ${ }^{10}$ or a truly peer-to-peer system could be used to generate decentralized decisions. ${ }^{11}$ Individuals would have incentives to develop reputations as fair arbitrators, since that would make them more likely to be selected for future insurance pools and thus earn to earn arbitral fees.

Existing insurance, of course, is more sophisticated than this, not merely redistributing premiums to insureds but also providing for the possibility that total claims might be in excess of premiums. Yet many types of insurance, covering many insureds with losses unlikely to be highly correlated, could work reasonably well with such a simple scheme. Moreover, it is possible to imagine blockchainbased insurance that would also allow for payouts to be greater or less than insureds' contributions. Investors might contribute to the pool as well, performing

\footnotetext{
${ }^{7}$ See, e.g., https://github.com/pirapira/ethereum-formal-verification-overview.

${ }^{8}$ See, e.g., https://bitshares.org.

${ }^{9}$ See, e.g., DON TAPSCOTT \& AlEX TAPSCOTt, BlockCHAIN REVOLUTION 104 (2016).

10 See, e.g., Vitalik Buterin (vbuterin), Decentralized Court, REDDIT (Apr. 16, 2016), https://www.reddit.com/r/ethereum/comments/4gigyd/decentralized_court/ [https://perma.cc/X9QC-3DRV] (proposing a "decentralized court" "by which a user could ask a question, expressed in the form of English text, and have a decentralized mechanism ... determine the answer, and then send a callback and a log to the user who asked the question")

${ }^{11}$ See infra paragraph accompanying note 29.
} 
a function similar to buyers of catastrophe bonds. ${ }^{12}$ Then, the smart contract protocol would need to specify a process for determining what percentage of the total pool would be awarded to insureds based on their claims. If the level of losses were unexpectedly high, then the investors might not recover all of the funds they invested; if they were lower or the same as expected, then investors would recover their funds, plus some portion of the funds provided by the insureds. A more elaborate design might allow for reinsurance.

Whether or not the payouts are guaranteed to equal the contributions to the pool, an insured would be hesitant to contribute to a pool as described so far, if the insured expected other insureds to be of higher risk. If payouts are simply proportional to losses, then the pool will be beset by adverse selection, ${ }^{13}$ with only insureds with the highest risk willing to join the pool. Lower-risk parties will either forego insurance altogether or will opt for traditional insurance, where an insurance company adjusts premia based on the risk of each insured. Meanwhile, moral hazard would likely rear its ugly head, if the rules of the insurance pool did not ban highly risky activities. ${ }^{14}$ The twin dangers of adverse selection and moral hazard, it might seem, would doom blockchain-based insurance by preventing it from performing perhaps the most important function of an insurance company: underwriting.

There are, however, at least two possible means of making payouts proportional to risk. The first approach is to change the arbitrator's assignment. Instead of measuring only the loss amount, the arbitrator would seek to estimate ex post the ex ante distribution of various possible loss levels. This would make it possible to determine the portion of the premium allocated to the loss level realized and the ex ante probability of that loss. The insured would then be credited with that portion of the premium multiplied by the ex ante probability. High-risk insureds would thus receive lower payouts. One can view this system as an ex post alternative to underwriting. Meanwhile, some insureds might exclude coverage for high-risk activities or find other means of committing to being low risk (such as installing fire protection devices), thus lowering moral hazard. This is a form of self-underwriting. The reward for doing so is that if a still-covered loss occurs, the arbitrator will conclude that the losses were lower probability and thus the payouts were higher.

The second approach to taking into account insureds' various risk profiles would be for blockchain-based insurance could develop a system of underwriting, thus making it more akin to existing forms of insurance. This system might piggy-

\footnotetext{
${ }^{12}$ See, e.g., Lawrence A. Cunningham, Securitizing Audit Failure Risk: An Alternative to Caps on Damages, 49 WM. \& MARY L. REV. 711 764-66 (2007) (describing market for such bonds).

${ }^{13}$ See George A. Akeriof, The Market for "Lemons": Quality Uncertainty and the Market Mechanism, 84 Q.J. ECON. 488 (1970) (providing the canonical explanation of the problem).

${ }^{14}$ See generally 44 AM. JUR. 2D INSURANCE $§ 1198$.
} 
back on existing insurance contracts, or alternative form contracts might be developed. Either way, a decentralized system of assessing the risk of a potential insured would be needed. For example, some third parties might specialize in certifying insureds for a fee. Investors would then take into account the reputation of these third parties in determining whether to cover some portion of the risk for an insured. The arrangement would thus be similar to that provided by Lloyds of London. ${ }^{15}$ Algorithmically, this is not much more complex to implement than the approach above. It insists on taking risk into account ex ante rather than ex post, thus providing greater predictability but at larger transactions costs. The principal challenge with this approach is that it could take longer to develop, as investors would only gradually be able to learn which third parties' evaluations to trust.

If blockchain-based insurance can overcome obstacles such as cryptocurrency instability to gain a foothold in the market, however, one virtue of the blockchain is that information on transactions would be publicly available. A critical function of insurance companies today is to provide actuarial expertise, based largely on proprietary data. If the blockchain makes publicly available all contracts, along with third-party certifications and ex post adjudications, then relevant data will be shared. Data, of course, must be analyzed. Possibly, such analysis will take the form of open-source code. Alternatively, market participants like certifiers and investors may independently analyze the data, obtaining a competitive advantage to the extent that their trade secret models are more accurate than their competitors'. Either way, potential insureds would be in a much better position to evaluate potential insurance contracts. The large expenditures of insurance companies on advertising, much of it largely uninformative, likely reflects the difficulty today that consumers have in evaluating potential insurers. With blockchain insurance, there are no insurance companies, but there might be other market participants whose credibility is at issue. Open data might allow for the creation of metrics to inform questions such as how commonly arbitrators are overturned on appeal and how much reinsurance counterparties have.

Prognosticating future market developments is always risky, and I do not mean to imply that blockchain-based insurance will necessarily upend the insurance industry as conventionally understood or even that it will earn substantial market share. Indeed, this chapter will identify significant obstacles to such insurance, and although these obstacles could be overcome, it is difficult to guess whether that might happen in a decade or even in fifty years. Even once the obstacles are gone, private ordering can take a long time. There are strong network benefits to existing insurance, and blockchain-based insurance would for the most part need to be built from the ground up. Finally, even if blockchain-based insurance is developed, it is

\footnotetext{
${ }^{15}$ See generally BUSINESS TRANSACTIONS SOLUTIONS § 231:62 (discussing the Lloyds of London marketplace).
} 
not clear what precise form such insurance would take-for example, whether the total amount of premiums to be returned to insureds will be set in advance.

The purpose of this chapter is not to resolve such questions, but rather simply to sketch out some ways that blockchain-based insurance might work- to establish a proof of concept rather than a prediction. This sketch, much of which has already been accomplished in this introduction, is needed to support this chapter's observations about how law might affect blockchain-based insurance. As suggested above, existing regulation of insurance carriers may boost blockchainbased insurance, because some forms of blockchain-based insurance may be beyond the reach of regulators, in much the same way as municipal regulation of taxi drivers allegedly helped ride-sharing services such as Uber. ${ }^{16}$ On the other hand, this perspective may underestimate the willingness of lawmakers to regulate blockchain-based insurance, for example by targeting purchasers, or to provide advantages like tax deductibility to providers of traditional insurance. Meanwhile, a foreign legal system could significantly boost the prospects of blockchain-based insurance by creating a fiat cryptocurrency or alternatively by creating a regulatory framework making it possible for premiums to be invested in real assets during the life of insurance contracts.

The chapter proceeds as follows. Part II describes how blockchain-based insurance might work, first identifying a limited role for the blockchain with traditional insurers and then expanding on this introduction's sketch of how the blockchain might facilitate insurance disintermediation - that is, the pooling of risk without insurance companies as conventionally conceived. Part III then documents how the legal system can make insurance expensive, thus providing a market opportunity for a new, unregulated product, and identifies legal obstacles to blockchain-based insurance.

\section{HOW BLOCKCHAIN-BASED INSURANCE WOULD WORK}

A recent report by McKinsey \& Co. is titled Blockchain-in-Insurance: Opportunity or Threat?. ${ }^{17}$ The report's discussion of the "threat" is limited to a single sentence: "As an innovative technology, blockchain presents a threat for incumbents in the form of innovative business models and/or cost advantages." 18 The report, however, does not elaborate what these "innovative business models" might be, focusing instead on potential benefits of the blockchain to incumbent insurance policies. An Ernst \& Young report on blockchain-based insurance takes

16 See, e.g., Katherine E. O'Connor, Along for the Ride: Regulating Transportation Network Companies, 51 TULSA L. REV. 579, 582 (2016).

${ }^{17}$ MCKINSEY \& CO., BLOCKCHAIN-IN-INSURANCE: OPPORTUNITY OR THREAT? (July 2016).

${ }^{18}$ Id. at 7 . 
a similar approach. ${ }^{19}$ Perhaps the assumption is that incumbent insurance companies will be as well positioned to take advantage of the opportunities offered by the blockchain in insurance as upstarts. These "opportunities," however, signal the possibility for broader disruptions than the reports acknowledge.

\section{A. With Traditional Insurers}

The McKinsey report suggests that the blockchain may provide a mechanism for customers to provide data to insurance and other companies without being subject to endless entry screens and need for verification. The report describes technology allowing a "customer [to] grant[] a company access to identity data when necessary for a contract closure." ${ }^{20}$ While this may seem relatively trivial, the report is correct to highlight it, because the easier it is for customers to share their information, the more likely customers will be to compare different companies' insurance products. But even if insurance companies can obtain customer information more easily, a significant explanation of customer loyalty lies in the difficulty of comparing insurance products. We will see below, however, that a public blockchain may make it easier for customers to determine which insurance product is likely to provide it with the best risk protection. ${ }^{21}$

The McKinsey report specifically identifies "smart contracts on top of a blockchain" as offering various benefits, such as "automation of claims handling" and providing "a reliable and transparent payout mechanism for the customer." 22 But, barring rare instances of checks lost in the mail, customers already know when insurance companies make payouts to them, and the use of permissioned blockchains will not guarantee faster delivery to the customer. The report notes that "a smart contract can ensure that the claim is only paid out if the car is repaired in a garage preferred and pre-defined by the insurer," 23 but insurance companies can easily enforce such restrictions absent smart contracts. The greater potential for smart contracts is that they might provide greater assurance to the customer that the insurance company will make appropriate payments when claims arise. But this will occur only if smart contracts change the process for resolving claims in a fundamental way, for example by allowing a third-party arbitrator to determine whether to honor claims.

19 ERnst \& Young, BlockChain In InSURANCE: APPLICATIONS AND PURSUING A PATH TO ADOPTION (2017).

${ }^{20} I d$. at 3.

${ }^{21}$ See infra Part II.B.3.

${ }^{22}$ MCKINSEY \& Co., supra note 17, at 4.

${ }^{23} I d$. 
The report also notes that the blockchain might reduce fraudulent transactions, by allowing for validation of documents, such as customer medical reports, and "detect[ing] patterns of fraudulent behavior related to a specific identity." ${ }^{24}$ But as the report notes, such benefits require "intensive cooperation between insurers, manufacturers, customers, and other parties." 25 Insurance companies might not have sufficient incentive to share data, particularly if their data provides them a competitive advantage. But upstart competitors relying solely on the blockchain would need to be transparent almost by necessity. If the transparency of blockchain-based insurance deters customers from engaging in fraud (perhaps those customers will continue to work with traditional insurers), blockchain-based insurance might gain a significant advantage over those insurers. Meanwhile, the report notes that reinsurance may be more feasible if insurance transactions are represented on the blockchain, ${ }^{26}$ but this too suggests that a form of competition featuring transparency may have some long-term advantages over existing proprietary competition.

\section{B. Without Traditional Insurers}

Neither the McKinsey nor the Ernst \& Young report considers the possibility that smart contracts might facilitate the development of an unregulated form of insurance. The legal system has long played a critical role in the insurance market. It is possible to imagine a world in which companies like telecommunications providers could furnish services even if the contracts they entered into with customers were not legally enforceable, ${ }^{27}$ as customers would recognize the reputational incentives that such providers would have to furnish services. But this seems far less plausible in the insurance context. Though relatively few insureds end up in coverage litigation with their insurance companies, the possibility of such litigation has a substantial disciplining effect. It assures customers that insurance companies will not simply walk off with their premiums if they determine that the funds being held for consumers exceed the present discounted value of profits from honest insurance provision. Smart

\footnotetext{
${ }^{24} I d$. at 5.

${ }^{25} \mathrm{Id}$. at 5 .

${ }^{26} I d$. at 6 . Similarly, the Ernst \& Young report notes that "P\&C insurers seeking clearer visibility into their reinsurance contracts and risk exposures may gain it through blockchain." ERNST \& YounG, supra note 19, at 4.

${ }^{27}$ For an argument that contracts sometimes can be self-enforcing, see Alan Schwartz \& Robert E. Scott, Contract Theory and the Limits of Contract Law, 113 YALE L.J. 541 (2003). Given that consumers generally do not read contracts, the mandated disclosure of contract terms may produce relatively little consumer benefit. See, e.g., OMRI BEN-SHAHAR \& CARL E. SCHNEIDER, MORE THAN You WANTED to KnOW: THE FAILURE OF MANDATED Disclosure (2014).
} 
contracts, however, provide an alternative form of guarantee to customers that no one will breach their promise walk off with their funds. They can thus serve as an alternative to the legal system, including regulation and adjudication.

Indeed, with the pure insurance pool model, insureds need not trust one another, so long as the smart contract provides assurance that total payouts will be equal to premiums. There is no party that has the ability with such an arrangement to take the premiums and run, assuming that the smart contracts cannot be exploited by hackers. It is this advantage that makes this type of blockchain-based insurance coverage more likely to develop initially than a full-blown substitute for the existing insurance system. But a pooling approach has its own challenges, as insureds must still be convinced that other contributors to the pool will not have some inherent advantage over them in claiming the funds ex post. Insureds must thus have some ability to trust an arbitrator, but we will see that careful design can limit the power of any single arbitrator and thus facilitate a pooling arrangement. Trustworthy adjudication will be even more important if the total size of payouts is not guaranteed to be equal to the total premiums, especially if a substitute for ex ante underwriting is used.

\section{Pooling Through Smart Contracts}

The smart contract insurance pool is straightforward in design. A smart contract would be produced as a form of open source software code. To purchase insurance, an individual or entity would digitally sign the smart contract. The smart contract would include virtual blanks for two important pieces of information. The first is the amount of cryptocurrency being contributed to the contract (which might be constrained by the smart contract to being within some range, to avoid both frivolously low coverage amounts and coverage amounts so high as to increase risk to other members of the pool). The smart contract might be considered incomplete until this money is paid, or the contract could be designed so that a specific premium is required, with the contract ceasing to be operational if a premium payment is not later made. The second type of information concerns the insurable interest. The simplest form this might take is a hash code uniquely identifying a document created by the insured and made publicly available that provides information about the interest insured. Insureds might fill out open source forms that solicit relevant questions about the insurable interest. Critically, placing the hash on a reliable blockchain using a suitably robust protocol such as proof of work makes it virtually impossible to change the document after its initial creation.

The smart contract would be governed by its code, but claim arbitrators would be expected to make their decisions according to contract terms applying to all insureds using that smart contract. The code for the smart contract might include a hash of a document containing such terms. (Again, the smart contract code itself could produce a hash, thus ensuring that the terms cannot be tampered with.) These 
terms might be designed to combat obvious forms of adverse selection. For example, the terms might provide that no coverage will be available if it turns out that the insured failed to disclose certain types of information, such as pre-existing conditions in a health insurance contract. Or, a fire insurance policy might combat moral hazard by barring coverage if it turned out that the insured failed properly to maintain smoke detectors. Meanwhile, individual insureds might add their own coverage restrictions to the contract. By eliminating coverage for some scenarios, the insured effectively allocates more of the premium to coverage in other scenarios, thus increasing payouts in those cases.

Specific exclusions, however, are not essential, so long as claim payouts are based on ex post estimates of ex ante risk. What is essential is that the contract specify, both with code and with instructions, how claims should be handled. A simple arrangement would work as follows: An insured with a claim will specify the maximum amount of the claim. To discourage frivolous and excess claims, the insured must pay some percentage of this amount (perhaps 5\%), but no less than a specified minimum, to fund the claim arbitrator. The arbitrator's role will then be to determine how much of the claim to allow. The arbitrator would do this by retrospectively allocating the premium across different types and levels of losses. That is, the arbitrator would estimate the ex ante probability of every type of loss and level of loss within that type and would then allocate the premium across these types and levels in the way that ex ante would most reduce risk. That should allow the arbitrator to determine what portion of the premium should be attributed to a loss of the type and level experienced. Then, the arbitrator would determine the type and level of loss actually experienced, multiply by the amount of the premium allocated to this loss, and divide this by the ex ante probability of the loss. The lesser of this number and the claim sought can be defined as the verified claim.

Consider the following very simple example. Suppose that an insured purchases car insurance and specifies no further exclusions. The arbitrator might determine that there was a $1 \%$ chance of a $\$ 10,000$ loss and a $2 \%$ chance of a $\$ 5,000$ loss. The optimal ex ante insurance premium would then have been $\$ 200$ $(0.01 * \$ 10,000+0.02 * \$ 5,000)$. If the insured in fact purchased $\$ 200$ in insurance, then this insurance would be allocated evenly between the two contingencies, as this would provide optimal insurance. If the insured only purchased $\$ 100$ in insurance, then that $\$ 100$ would be allocated entirely to insurance against the chance of the higher loss, as this can be shown to minimize the variance of loss. For a $\$ 150$ premium, $\$ 100$ would be allocated against the $\$ 10,000$ risk and $\$ 50$ would be allocated against the $\$ 5,000$ risk. Of course, in reality there might be many more levels of loss, as well as possibly losses of different types (say, vehicle damage and rental costs while the vehicle is being fixed). Still, so long as the arbitrator can estimate the ex ante probabilities of these events - and in time, the 
transparency of the blockchain should improve an arbitrator's accuracy in doing so - it should be straightforward to determine the optimal insurance allocation.

Smart contracts would be paid out all at once, at the conclusion of the policy period. (An insured would be able to sell the right to a smart contract payment at an earlier time.) Particularly with early smart contracts, this should also facilitate making ex ante assessments, as the arbitrator would at least be able to look at data associated with all contracts and claims. If verified claims exceed the total premiums, then an insured with a verified claim would receive the verified amount multiplied by the quotient of total premiums divided by total verified claims. The smart contract, however, also must address the contingency in which verified claims are less than total premiums. One possibility is to pay extra on claims. This may be an appropriate approach if there is a concern that arbitrators may pay too little on claims. Another possibility is to refund the remaining amount to all insureds in an amount proportional to their contributions. Mutual insurance companies often take a similar approach, paying dividends to insureds when claim payouts are sufficiently low. ${ }^{28}$ This approach avoids providing a windfall to those who have verified claims, and it is essential at least if there are no verified claims.

All of this should be straightforward to implement in a smart contract, once a smart contract platform is suitably developed. Calculating payouts is a matter of arithmetic that can easily be implemented in a computer algorithm. The hard work is done by the arbitrators, and the most important function of a smart contract is to provide a suitable mechanism for selection of an arbitrator. A smart contract might just select the arbitrator in advance. This can technically be implemented by including in the smart contract the public key of the arbitrator, who would then use the corresponding private key to confirm particular awards. The public-private key pair might be owned by an entity or by an individual. Indeed, this might well be the entity that constructs and markets the particular smart contract. So long as this entity is sufficiently trustworthy, insureds should be willing to participate.

There are two possible concerns about such an arrangement, however. First, particularly if the goal is to avoid legal regulation, it might be desirable for the arbitrator to be anonymous. This concern may be overstated, however, particularly since the arbitrator could be based in a friendly jurisdiction like the Cayman Islands, reviewing evidence submitted electronically. Second, and more seriously, there is a danger that the arbitrator might engage in fraud, for example by adding one or more spurious insurance contracts to the pool and then filing false claims that are then given higher verified values. Over time, such a scheme is likely to be uncovered. At least, it would be apparent that verified claims for smart contracts resolved by the arbitrator tended to be high, and this should lead individuals seeking the best deal to contract with other insurance pool providers. In the long run,

${ }^{28}$ See, e.g., https://www.investopedia.com/terms/a/annual-dividend.asp. 
arbitrators might develop sufficient reputations that would make it more profitable to arbitrate honestly than to submit false claims. But this could at least create problems in the short term.

A slightly more complex arrangement would allow for the smart contract provider to designate a pool of arbitrators, with the arbitrator for any particular claim selected at random from the pool. A further improvement is to allow one arbitrator's judgment to be challenged by an appeal to a second arbitrator. The insured might be allowed a rehearing if the insured were willing to pay the required arbitral fee again, or perhaps only if the insured were willing to pay some higher fee. Meanwhile, a third party might be allowed to pay the same amount to challenge an initial arbitrator's ruling as being too large. The right to be that third party might be auctioned to the third party willing to pay the most (but no less than the arbitral fee) for the right to receive any decline in the size of the verified claim. Any auction proceeds in excess of the arbitral fee could be added to the premium pool and thus distributed among verified claimants. Further refinements could be made. For example, if an appeal results in a sufficiently different valuation, the initial arbitrator might forfeit the arbitral fee, or even be required to forfeit a bond. The point here is not to determine the optimal contract, something that could be worked out with time, but simply to indicate that relatively simple systems for choosing and incentivizing arbitrators and creating a form of appellate adjudication could be devised.

Perhaps the most ambitious approach to arbitration would be one that I discussed in earlier papers: the use of peer-to-peer adjudication. ${ }^{29} \mathrm{I}$ will not repeat a full description of peer-to-peer adjudication here, but its most important characteristic is that no arbitrator need be selected. Instead, anyone would be able to offer a suggested resolution of the claim. A participant in the resolution process, however, would be given economic incentives to announce a resolution as close as possible to any resolution that a subsequent participant in the process might provide. A participant who announces a valuation closer to the later valuation the the prior valuation will earn currency, while a participant who pushes the valuation in one direction only to have the valuation pushed back in the opposite direction will generally lose currency. Because a participant will not know who might participate later, the incentive of each participant is to seek out the "focal" resolution to the question of how large the verified claim should be. The provisions of the smart contract concerning how claims should be resolved are likely to determine what participants in this market believe is focal.

29 See Michael Abramowicz, Cryptocurrency-Based Law, 58 ARIZ. L. REV. 359 (2016); see also Abramowicz, supra note 1 (applying peer-to-peer adjudication to the insurance context). 


\section{Underwriting, Investment, and Reinsurance}

Just as one might develop much more complex mechanisms for resolving claims than the one specified here, so too might one develop more complex insurance schemes, including insurance schemes where total payouts do not necessarily equal total premiums paid. One means of accomplishing this would be for the smart contract sponsor to commit funds to the pool (or to find outside investors willing to commit funds). Instead of the insureds' receiving a refund if total premiums are in excess of verified claims, the smart contract provider would receive the difference, but the provider could lose some or all of the funds if verified claims exceed premiums. This approach magnifies the importance of insureds' trust in the arbitration process. Insureds may have more faith in that process if the arbitrators' responsibility is less open-ended than making ex post assessments of ex ante probabilities, and so it is likely that once the market moves away from the pool model, there will be a concomitant tendency for insurance contracts to become more rule-bound.

An approach of this sort will be essential in any insurance context in which losses are likely to be highly correlated-for example, property insurance that includes protection against hazards like hurricanes or earthquakes. A pool approach might still be viable for insurance of that sort, but the risks would need to be diversified. Smart contract sponsors, for example, might seek out smart contract holders from many different locations, to minimize the risk that total claims will greatly exceed total premiums. But if the adjudicative process were someday to become sufficiently trusted, then there is no reason that blockchain-based insurance cannot protect against highly correlated losses in much the same way as regular insurance. It is also possible to imagine hybrid approaches. For example, the smart contract provider might place aside funds to be added to the pool only in the event of some specific contingency, for example a hurricane with damages in a particular region exceeding some threshold. The smart contract provider might even raise such funds from third parties looking for high returns, thus creating an investment vehicle similar to catastrophe bonds. ${ }^{30}$ With this contingent financing, insureds might still face some risk that losses might be unexpectedly high as a result of a statistical blip, but would receive assurance that sufficient funds would be available in the event of an identifiable catastrophe

Another means of protecting insureds in the event of high losses would be for some form of blockchain-based reinsurance to emerge. This could be implemented in smart contracts as well and provide a means for risk pooling to occur beyond the limits of any particular smart contract. For example, a smart contract sponsor might provide that some portion of premiums for the smart

\footnotetext{
${ }^{30}$ See Cunningham, supra note 12 (discussing catastrophe bonds).
} 
contract will be placed aside, with the aggregate invested into a reinsurance smart contract. That smart contract might itself take the form of an insurance pool, with payouts made to the smart contracts in the pool with the most unexpectedly high losses. Of course, just as the insurance industry features tiers of reinsurance, so too could smart insurance contracts on the blockchain.

It might also be possible for blockchain-based insurance to increase its credibility by piggybacking on existing legal regimes. For example, a smart contract sponsor based in the Cayman Islands might wish to use certain real assets as security for smart contracts in the event that claims are sufficiently high. Meanwhile, the smart contract might provide for adjudication in a traditional court or arbitral body to determine whether those real assets must be sold so that the proceeds can be added to a smart insurance pool. One defect of the smart contract arrangements described so far is that assets such as premiums are tied up in the smart currency during the contract period, rather than invested, as would occur with typical insurance arrangements. But if a single jurisdiction credibly commits to enforcing contracts related to blockchain-based insurance, regardless of whether those contracts accord with the insurance law of other jurisdictions, then that provides a nexus between the cryptocurrency and the broader financial world. Different jurisdictions might perform different roles-supporting a fiat cryptocurrency, performing adjudication, recognizing the possibility that a smart contract may be a beneficial owner of real assets ${ }^{31}$ and enforcing judgments accordingly - but a single jurisdiction might determine that it could benefit by serving as a virtual host for smart contracts, in much the same way as Delaware has profited from its domination in corporate law charters.

\section{Consumer Information}

Blockchain-based insurance is nonexistent, and even if it emerges, it will initially be unfamiliar. Most insurance customers will at first be more comfortable sticking with established players. Yet the radical transparency of such insurance makes it plausible that consumers might learn that smart contracts are trustworthy, and more than that, consumers might be able to determine which smart contracts are most appropriate for their particular circumstances. The defining differences between smart contracts will be the code governing them and the instructions for arbitrators. Media companies like Consumer Reports or the Wall Street Journal might review such documents and rate these contracts. Over time, more sophisticated ratings might be developed based on the results of adjudications for different smart contracts.

\footnotetext{
${ }^{31}$ See Abramowicz, supra note 29, at 413 (discussing the possibility that a cryptocurrency could own property).
} 
It is also possible that further smart contracts might be developed to provide guidance to consumers. For example, third parties might contract with insureds to rate insureds' likely customer satisfaction with different smart contract providers. The third parties might be compensated based on the degree to which their assessments proved accurate, with the compensation formulas depending on the third parties' performance across many smart contracts and thus not dependent solely on the vagaries of any single customer's experience. Such third parties would in effect serve a role of insurance brokers, but unlike traditional insurance brokers, would be paid only to the extent that they provided useful information to consumers about their likely satisfaction. This would give the third parties some incentive to determine which smart contracts might be most appropriate for which customers. In principle, it may be possible for similar institutions to evolve with traditional insurance, but it is much more straightforward in a world in which customers can simply be required to assess their satisfaction ex post and these values can automatically determine brokers' success.

\section{THE LAW'S ROLE IN BLOCKCHAIN-BASED INSURANCE}

Parts I and II have described in detail how blockchain-based insurance might work, but that still leaves the fundamental question of whether blockchainbased insurance has any inherent competitive advantage over ordinary insurance. The blockchain may well be an overhyped technology. At its core, a blockchain has no technical advantages over an ordinary database, and indeed the challenges of scaling blockchain technology may mean that blockchains will often be inferior to databases. ${ }^{32}$ If the blockchain is to serve a significant role in the insurance market, it is likely to be not because the technology is revolutionary as a database technology, but because a cryptocurrency armed with smart contract capabilities can escape legal regulation. Indeed, the goal of escaping regulation may well be a principal motivating factor in some other smart contract projects, such as augur.net, a decentralized prediction market that can be used for sports gambling.

This section addresses two questions: To what extent does legal regulation create expenses for traditional insurance carriers that blockchain-based insurance would not need to bear? And, to what extent could legal regulators successfully defend the project of insurance regulation by blocking unregulated blockchainbased insurance? This section does not address the broader question of whether blockchain-based insurance on the whole would improve social welfare. There are significant benefits to many existing forms of insurance regulation, for example in protecting consumers from fraud. Just as some investors lost money in insecure

32 See Preethi Kasireddy, Blockchains Don't Scale. Not today, at Least. But there's Hope., HACKERNOON, Aug. 23, 2017, https://hackernoon.com/blockchains-dont-scale-not-today-at-leastbut-there-s-hope-2cb43946551a. 
Bitcoin-based banks, there is a danger that investors might lose money as a result of poorly designed blockchain-based insurance contracts. The ultimate question, not addressed here, is whether the transparency of the blockchain and smart contracts could lead to a form of private ordering that is equally or more effective in providing value to insureds.

\section{A. The Expense of Law}

\section{Compliance}

Smart contract providers might not need to employ lawyers to ensure compliance with state, national, and international insurance regulation. The potential savings from direct compliance activities, however, may be small. A recent survey of property and casualty insurers determined that the insurers' average corporate and regulatory compliance expenses amounted to $0.19 \%$ of premiums. ${ }^{33}$ By itself, this is not a sufficiently large amount of money to make a compelling case for smart contracts. It is quite small relative to expenses overall. In the first half of 2016, the expense ratio for property-and-casualty insurers in the United States was $27.7 \% .{ }^{34}$ Of course, without insurance companies, other expenses contributing to this ratio would also be eliminated. Once the smart contract exists, all that is needed are willing insureds, arbitrators, and, if applicable, investors who provide a cushion in the event of high claims. To be sure, arbitrators will demand compensation. But this suggests that the most relevant savings are not directly from compliance activities, but from other sources, such as reduced marketing expenses, reduced costs associated with processing claims, and reduced inefficiencies resulting from legal compliance that forces insurers to adopt inefficient contracts.

\section{Adjudication}

There is no inherent guarantee that claims processing will be cheaper with smart contracts than with traditional blockchain-based insurance. Indeed, a strong argument against the insurance pool is that every insurance claim will result in some form of adjudication, as the arbitrator will need to determine ex ante probabilities of losses and thus allocate premia, in addition to determining whether the claimed loss occurred. Yet much of this work will likely not be repeated from one arbitration to another. Especially if there is some form of appellate review, arbitrators will have some incentive to explain their decisions, and an arbitrator will likely start by

33 See http://www.pciaa.net/industry-issues/erm-emerging-risks/news/emerging-risks-regulatorycompliance.

${ }^{34}$ NAT'L ASS'N INS. COMM'RS, THE CENTER FOR INSURANCE POLICY \& RESEARCH, 2016 MID-YEAR U.S. PROPERTY AND CASUALTY INSURANCE INDUSTRY REPORT (2016). 
looking at similar past decisions to determine how to allocate ex ante probabilities. The types of information relevant to determining whether a loss occurredphotographs, statements from witnesses, and so forth-are likely to be relatively standardized. So too are the types of information likely to be relevant to assessing ex ante probabilities, particularly information that shows the level of care that the defendant was exercising. Just as precedent is valuable in traditional adjudication, so too might it be used even in an informal system of adjudication on the blockchain. ${ }^{35}$

Inevitably, there will be some claims that require arbitrators to exercise judgment in certain respects, but the informality of the arbitration process should allow arbitrators to focus specifically on these aspects of claims. Part of the expense of the legal system owes to its formality, as well as to regulations requiring law degrees and bar admissions for lawyers. Of course, there are benefits to such formality, and an ultimate question in assessing blockchain-based insurance is whether a sufficiently strong adjudication system can be designed without these formal processes. Perhaps the arbitration process as described as above will not be sufficient, but a virtue of private ordering is that aspects of the system that prove problematic can be improved upon, without the necessity for revolutions in civil procedure. For example, if a perception develops that there is too much fraud, then smart contracts might provide for benefits to whistleblowers who identify such fraud.

Similarly, if the adjudicative process is too open-ended, the system can rely more on underwriting. Yet, there are strong reasons to believe that a system of smart contracts will rely more on standards than on rules. This may seem counterintuitive; it might seem that a mechanical system like a smart contract necessarily will require unambiguous rules. But that is impossible. Any contract that relies not just on code but also on human language to refer to events in the real world, as any insurance contract must, will necessarily require the exercise of judgment. We might tolerate a greater degree of subjectivity with smart contracts so long as arbitrators have incentives to make decisions as other arbitrators would, rather than according to their whim or political preference, and the appellate process can provide such incentives.

\footnotetext{
${ }^{35}$ For a skeptical view on adjudication for smart contracts, see Jeremy M. Sklaroff, Comment, Smart Contracts and the Cost of Inflexibility, 166 U. PA. L. REV. 263, 300-02 (2017). Sklaroff argues that with adjudication by smart contracts, parties "cannot cite precedent to incorporate previous decisions, and may not even know what those previous decisions were." Id. at 301-02. But adjudicative opinions could be made public, and adjudicators (who wish to avoid being overturned on appeal) will have incentives to make their arguments clear and to give appropriate weight to arguments made in the past. A full analysis of smart contract-based adjudication is a project for future development.
} 
One reason that insurance contracts are relatively rule-like is that rules provide protection against legal decisionmaker biases. Sometimes, these biases may be essentially random, with some judges biased in favor of insurance companies and some biased in favor of insureds. But most bias will be of the latter type. This is true for two reasons. First, the doctrine of contra proferentum provides that ambiguous policy provisions will be interpreted against the insurance company. ${ }^{36}$ Second, juries may have a natural bias to favor insureds, especially when the insureds are individuals. ${ }^{37}$ Collectively, these two pressures will push insurance companies in the direction of using clear rules, rather than relying on standards. Rules are inevitably overinclusive and underinclusive, and this may lead the companies to adopt inefficient contracts, relative to those they would adopt in a world in which they did not expect bias in adjudication.

Of course, it is possible that arbitrators may have their own biases, but individual monetary incentives seem likely to go a long way toward providing fairness incentives. Moreover, with an insurance pool, if arbitrators are systematically biased, that will have little effect. If, for example, every insured receives a valuation $20 \%$ higher than it should be, then all claimants will still receive the same amount of money as if this did not occur, since payouts are proportional to verified claims. Some bias might still inhere in the initial question of whether a covered loss occurred at all, and fraudulent or generous claims will come at the expense of other policyholders making claims. But if the problem is serious, providers of smart contracts might choose different arbitrators who they are confident will not too easily allow weakly supported claims.

\section{Regulation}

Perhaps the greatest market opportunities for unregulated insurance will arise where regulations cause market distortions. For example, laws may prevent insurers from taking into account applicants' genetic data in pricing coverage. ${ }^{38}$ Should widespread whole genome testing become available, these laws threaten to create adverse selection problems, as individuals with greater susceptibility to health problems may be most likely to purchase health and life insurance. ${ }^{39}$ If this occurs, there will be a market opportunity to sell unregulated insurance to individuals lucky enough to have genes that make them lower risk. As discussed below, there may be challenges to offering unregulated blockchain insurance, but

\footnotetext{
${ }^{36}$ See, e.g., 5 L. TOXIC TORTS § 31:65 (2017).

${ }^{37}$ See supra note 3.

${ }^{38}$ See, e.g., MASS. GEN. LAWS ANN. 175 § 108I (2006).

${ }^{39}$ See, e.g., Chetan Gulati, Genetic Antidiscrimination Laws in Health Insurance: A Misguided Solution, 4 QUINNIPIAC HEALTH L.J. 149 (2001).
} 
assuming that such insurance can exist, the market would be able to avoid regulations that cross-subsidize those with less healthy genes. My argument here is positive not normative; there are strong arguments for preventing genetic discrimination, ${ }^{40}$ and perhaps even stronger ones for preventing race discrimination in insurance. ${ }^{41}$ The point is simply that if the law prevents efficient contracting between insureds and insurers, that provides a competitive advantage to blockchain-based insurers that avoid regulation.

Other forms of regulation may similarly create market opportunities. Consider, for example, rate regulation. If rate regulation has the effect of cartelizing the industry and raising prices, unregulated insurers may be able to undercut existing prices. If, however, rate regulation tends to lower prices, ${ }^{42}$ that can lead to supply shortages, ${ }^{43}$ and blockchain-based insurance may fill the void by offering coverage. Meanwhile, coverage mandates can create opportunities for blockchainbased insurers. If all health insurance purchasers must provide maternity coverage,${ }^{44}$ then individuals who are confident that they will not need such coverage may purchase cheaper insurance. Similarly, some states provide that policies shall be incontestable after a certain period of time, meaning that false statements can no longer invalidate the policy. ${ }^{45}$ If this is inefficient, either because it means that honest policyholders are cross-subsidizing fraudsters or because it forces insurance companies to spend funds in excessive ex ante monitoring of insureds, there may again be a market opportunity for unregulated insurance.

The question, of course, is how great the market opportunities are. Insureds presumably already could purchase offshore insurance and submit claims over websites, yet such markets have not materialized as significant competitors to traditionally provided insurance. This may, however, be in part because insureds might not fully trust offshore insurers, a problem that smart contracts may address. Meanwhile, if smart contract-based insurance is administratively cheaper than traditional insurance, that provides further market opportunities.

\footnotetext{
${ }^{40}$ But see Sonia M. Suter, The Allure and Peril of Genetics Exceptionalism: Do We Need Special Genetics Legislation?, 79 WASH. U. L.Q. 669 (2001) (noting that issues may be similar to those involved in medical discrimination).

${ }^{41}$ See, e.g., Jill Gaulding, Race, Sex, and Genetic Discrimination in Insurance: What's Fair?, 80 CORNELL L. REV. 1646 (1995).

${ }^{42}$ Rate regulation may lower prices in the short term but raise them in the long term. See Angelo Borselli, Insurance Rates Regulation in Comparison with Open Competition, 18 CONN. INS. L.J. 109 (2011).

${ }^{43}$ See, e.g., Paul L. Joskow, Cartels, Competition and Regulation in the Property-Liability Insurance Industry, 4 BELL J. ECON. \& MGMT. SCI. 375 (1973).

${ }^{44}$ See, e.g., 42 U.S.C. $\$ 2000 \mathrm{e}(\mathrm{k})(2012)$.

${ }^{45}$ See, e.g., CAL. INS. CODE $§ 10206$ (2017).
} 


\section{B. Legal Challenges}

\section{Legality}

While legal regulation of insurance may create market opportunities for unregulated insurance, the possibility that lawmakers will seek to regulate unregulated insurance creates an obvious obstacle. The challenge is that if insurance is sold entirely through a cryptocurrency, it may be difficult to regulate. The government, however, may still have several possible approaches to blocking unregulated insurance.

First, the government might seek to regulate purchasers of insurance directly. Such regulation could be quite effective, particularly because the most obvious implementations of blockchain-based insurance require that insurance policies be stored transparently on the blockchain. The question is whether governments are willing to target consumers of insurance, rather than producers. If the government did decide to target consumers, the question then becomes whether such insurance might continue to exist without requiring consumers to identify themselves. Plausibly, information could be stored in encrypted form, but at least the arbitrator will need to be able to read an unencrypted version of the policy in determining whether to pay out claims. Conceivably, the government could pose as arbitrators to perform a sting operation against those filing insurance claims. Even less extreme action, however, could undermine aspects of the use case for blockchain by making it less transparent.

Second, the government might seek to ban the underlying cryptocurrency. China has aggressively cracked down on Bitcoin, ${ }^{46}$ illustrating that a regulatory ban is at least possible. But such a crackdown is far easier in a country in which the Internet is pervasively regulated. It seems unlikely that the United States or European countries would enact Internet filtering to prevent consumers from contacting insurance sites. More plausibly, the government might regulate financial exchange transactions into and out of a cryptocurrency. Blockchain-based insurance could be considerably hampered if it were impossible to use a credit card or a bank account to purchase (or receive the sale proceeds of) cryptocurrency. ${ }^{47}$ It will be difficult, however, for government officials to eradicate black markets, which might also be used for other troubling uses of cryptocurrency, such as paying extortion demands from ransomware developers. The question is whether government regulation adds enough hassle to cryptocurrency transactions to make blockchain-based insurance infeasible. At this point, the government has shown little interest in banning Bitcoin or Ethereum, and it may be impractical for the

\footnotetext{
${ }^{46}$ See Chen Jia, Crackdown Signals End of Illegal Exchanges, CHINA DAILY, Sept. 19, 2017, at 13.

${ }^{47}$ Unlawful Internet Gambling Enforcement Act of 2006, Pub. L. No. 109-347, tit. VIII, 120 Stat. 1952 (codified at 31 U.S.C. $\S \S 5361-5367$ (2006)).
} 
government to add regulatory controls once the public depends on these cryptocurrencies.

\section{Legal Requirements}

The legal system, however, may be able to thwart the development of particular blockchain-based insurance markets by requiring individuals to purchase legally regulated insurance. For example, drivers are generally required to purchase automobile insurance, ${ }^{48}$ and unregulated blockchain-based insurance presumably would not qualify. That does not necessarily entirely eliminate the possibility of blockchain-based insurance for additional coverage above and beyond that provided by insurance companies, such as for optional collision coverage. Meanwhile, to the extent that the law provides tax breaks for insurance, thus subsidizing legally recognized insurance, blockchain-based insurance will be at a considerable disadvantage. For example, life insurance proceeds are generally excludable from gross income under the Internal Revenue Code. ${ }^{49}$ Any uncertainty about whether such income would be excludable would likely doom that form of blockchain-based insurance, at least unless beneficiaries of such policies evade their tax liabilities, for example by disguising their receipt of life insurance proceeds.

\section{Legal Support for Blockchain-Based Insurance}

It is not inevitable that the legal system will treat blockchain-based insurance disadvantageously. Existing insurance companies have rents to protect and can thus be expected to lobby to cement their existing advantages and disadvantage blockchain-based insurance. But such efforts are not always successful. Taxicab companies, for example, have been mostly ineffective in countering ride-sharing services such as Uber, which have greatly reduced the value of medallion licenses. ${ }^{50}$ Blockchain-based insurance could follow a similar path, in which customers purchase policies when their legal status remains uncertain but then provide pressure on legislators to allow such insurance.

If for these or other reasons, a legislature wanted to promote blockchainbased insurance, how might it do so? First, the law might explicitly allow such insurance and provide that blockchain-based insurance contracts are unenforceable in court. This would ensure continued evolution and competition in the design of arbitral mechanisms. Second, the law might allow for courts to be used to enforce

\footnotetext{
48 See, e.g., VA. CODE. ANN. § 46.2-439 (2017).

49 See I.R.C. § 101.

${ }^{50}$ See Uber's Heavy Impact on Taxi Industry Is Plainly Seen in the (Falling) Numbers, N.Y. BuS. J., Jan. 8, 2015.
} 
promises that cannot be enforced by smart contracts alone, such as promises to use property recognized by the traditional legal system as security for blockchain-based insurance contracts. Third, if some degree of regulation is to be retained, these regulations should be tailored to blockchain-based insurance, recognizing that there may be no insurance company associated with any particular smart contract to regulate. Thus, regulation should directly affect insureds, for example by providing penalties should insureds release types of information that should be irrelevant to insurance pricing, such as genetic information. Fourth, and most radically, a legislature might create a fiat cryptocurrency, denominated in the same currency unit as the main currency. A legal commitment that the government will exchange cryptocurrency units for dollars or other internationally recognized currency would reduce the risk associated with the volatility of the cryptocurrency itself. This could facilitate blockchain-based insurance not only in that country, but also elsewhere. The absence of these forms of support could make it much more challenging for blockchain-based insurance to emerge.

\section{CONCLUSION}

The skeptical perspective on blockchain-based insurance is that the blockchain merely facilitates transactions that easily can be performed without the blockchain and indeed that were performed at relatively low transactions costs without the Internet. The bullish case for blockchain-based insurance highlights the possibility that such insurance could exist largely separate from the legal system, freeing it both of burdens associated with regulation by the administrative state and the expense associated with traditional adjudication in courts. This would require development of software code and accompanying contracts that insureds will trust, and such trust would likely come only with time. In the long run, however, it is plausible that more informal adjudicative structures could be cheaper and thus allow for more efficient, cheaper insurance contracts. Blockchain-based insurance also might be more transparent and trustworthy than traditional insurance, perhaps making it easier for consumers to determine which insurance is most appropriate for their needs. The legal system poses challenges for blockchain-based insurance as well. There is both the danger that the legal system might effectively ban such insurance and the possibility that even if blockchain-based insurance avoids regulation, the absence of the legal system will cause inefficiencies, for example by preventing the effective investment of premiums. Finally, if blockchain-based insurance does prosper, that might provide economic efficiency but at the expense of other goals of the legal system, such as ensuring that certain factors not be taken into account in insurance pricing. 